\title{
Unanticipated hospital admission after outpatient laparoscopic cholecystectomy
}

\author{
Elise V Bojsen", and Mogens R Madsen*1 \\ ${ }^{1}$ Department of Surgery, Herning Regional Hospital, Denmark
}

\begin{abstract}
Background: Outpatient laparoscopic cholecystectomy has proven both safe and feasible and is widely accepted as surgical treatment of symptomatic cholelithiasis. The aim of this study was to identify reasons for unanticipated hospital admission as well as readmission within 30 days after outpatient laparoscopic cholecystectomy.

Methods: Patients who underwent outpatient laparoscopic cholecystectomy during a 3-year period at Herning Regional Hospital were identified and data collected from the patients' electronic case records.. Information about biographical data, indication for surgery, the surgical procedure and outcome was extracted. Statistical analysis was made using $\chi^{2}$ test, Fisher's exact test and Student's t-test.

Results: A total of 441 consecutive patients were included in the study. 337 (76\%) were female and 104 (24\%) were male. The median age was 45 years and median BMI was 275. All patients had ASA-score I or II. 434 patients were operated due to symptomatic cholelithiasis alone. Other indications were formerly verified episodes of cholecystitis, choledocholithiasis or pancreatitis, and a few patients were operated due to gallbladder polyps. Median operating time was 69 minutes. 5 patients $(1 \%)$ needed conversion to laparotomy during surgery. Excluding these did not affect the median operating time. 72 patients (16\%) were unexpectedly admitted to hospital postoperatively mainly due to intraoperative placement of a suction drain, excessive postoperative pain and postoperative nausea and vomiting. Operating time was found to be the only significant predictor of unanticipated admission $(\mathrm{P}<0,001)$. Median duration of hospitalization for these patients was 1 day and 15 patients (21\%) were discharged later at night on the day of surgery. Pain, haematoma/bleeding and choledocholithiasis were the main reasons for the 29 patients (7\%) being readmitted within 30 days past surgery. Eight patients needed subsequent laparoscopic re-surgery.
\end{abstract}

Conclusion: Reducing the use of suction drains as well as actions to reduce postoperative nausea and vomiting may decrease the rate of unanticipated admissions after outpatient laparoscopic cholecystectomy. Furthermore prolonged opening hours in the outpatient clinic or future scheduling of outpatient laparoscopic cholecystectomies for morning operation times only may decrease the rate of unexpected admissions of short duration.

\section{Background}

Since the first laparoscopic cholecystectomy (LC) was performed in 1985 this operation has become widely accepted and is now the standard operation for surgical treatment of symptomatic cholelithiasis [1]. The LC patients have a shorter hospital stay and less pain postoperatively compared to patients treated with open cholecystectomy (OC) [2]. The many years of experience with the LC have resulted in increasingly more patients being operated in an outpatient setting and several studies have proved this to be both safe and feasible [3-5]. At Herning Regional Hospital, Denmark, outpatient LC is also offered to patients, who are judged fit for this procedure. However, some patients scheduled for outpatient LC will experience an unanticipated admission to a hospital ward after the procedure or will be re-admitted to the hospital during the early postoperative period. More studies have tried to identify factors influencing this problem including conversion to OC, operating time, intraoperative placement of a suction drain, excessive postoperative pain, urine retention, nausea/ vomiting, haematoma, infection, acute pancreatitis etc [6-9]. The aim of this retrospective study was to identify the reasons for unexpected admission as well as re-admission for patients who underwent LC as an outpatient procedure.

\section{Patients and methods}

Patients, who underwent LC as an outpatient procedure during a three year period at Herning Regional Hospital were retrospectively identified using the hospital's electronic registration system. Patients selected for outpatient LC should meet certain criteria defined by the Department of Anaesthesiology (Table 1).

The operations were performed in the of clinic, which located within the hospital has its own operating rooms and its own recovery rooms. If patients - for whatever reason - were not capable of going home, when the department closes at $17 \mathrm{PM}$, they were admitted to a hospital ward. Data were extracted from the patients' case files, including biographic data (gender, age, BMI, ASA-score), information about the indication for surgery, the surgical procedure (operating time, conversion to $\mathrm{OC}$ ) and outcome (unexpected admission and/or readmission within 30 days post-surgery and the reasons for these events as well as the length of hospitalization).

For statistical calculations of proportions the $\chi 2$-test with Yates' correction for discontinuity was applied. If the expected number was less than five, Fisher's exact test was used. For continuous variables

Correspondence to: Mogens R Madsen, Herning Regional Hospital, Gl. Landevej 61, 7400 Herning, Denmark, Tel: +45-7843-5271; Fax: +45-7843-5279; E-mail: mogmad@rm.dk; Mogens.R.Madsen@vest.rm.dk

Key words: laparoscopic cholecystectomy, outpatient surgery

Received: February 02, 2017; Accepted: February 26, 2017; Published: March 02,2017 
Student's t-test or Mann-Whitney's U -test was used, when appropriate. The level of significance was 0.05 . Data are presented as medians unless otherwise indicated.

\section{Results}

A total number of 441 consecutive patients were included in the study (Figure 1).

Biographical data can be seen in Table 2.

All patients had ASA score I or II, and indications for cholecystectomy are listed in Table 3.

Most patients had only symptomatic cholelithiasis (pain attacks). Twenty patients had previously had an episode of cholecystitis and 17 patients had experienced episodes of stones in choledochus prior to surgery. Two of the 441 patients did not full-fill the criteria for outpatient surgery, but this did not influence the overall results.

The median operating time was 69 minutes and 5 patients (1\%) had their operation converted from LC to OC. Reasons for conversions were unclear anatomy $(\mathrm{n}=2)$, adhesions $(\mathrm{n}=2)$ and bleeding $(\mathrm{n}=1)$. When excluding these 5 patients the median operating time remained 69 minutes.

\section{Unanticipated admission}

Seventy-two patients (16\%) experienced an unexpected admission after surgery, but 15 of these (21\%) were discharged from the ward later on at night the same day. Table 4 lists the indications for cholecystectomy in those patients unexpectedly admitted after surgery. Twenty patients were scheduled for LC due to prior cholecystitis and 6 (30\%) of these were admitted unexpectedly after surgery. However, this was not statistically different from patients having performed LC with other indications $(\mathrm{P}=0,6)$.

Reasons for unexpected admission are listed in table 5. The top- three reasons for unexpected admission were intraoperative placement of a suction drain, excessive postoperative pain and dizziness /nausea / vomiting also known as postoperative nausea and vomiting (PONV). Five patients needed laparoscopic re-surgery. Four of those were operated due to bleeding and the ifth due to an aberrant bile duct resulting in cholascos. Patients unexpectedly admitted after surgery had a median stay at the hospital of 1 day. Table 6 and 7 compares the patients who experienced unexpected admission to those discharged after surgery as planned in relation to age, BMI and operating time. Analysis of variance (ANOVA) showed that operating time was statistically significantly associated with unexpected admission $(\mathrm{P}<0,001)$, whereas age and BMI were not.

Table 1. Department of anaesthesiology - Criteria for outpatient LC

Expected operating time less than 75 minutes

Age above 2 years

ASA-score I, II or stable III

Well cooperating patient or relative

Possibility to be picked up after surgery

Post-surgery surveillance for at least 24 hours by an adult relative

No anamnestic history with complications in relation to anaesthesia

Table 2. Biographic data $(n=441)$

\begin{tabular}{|c|c|c|}
\hline Variable & $n$ & $\%$ \\
\hline \multicolumn{3}{|c|}{ Gender } \\
\hline Female & 337 & 76 \\
\hline Male & 104 & 24 \\
\hline Total & 441 & \\
\hline Age median (range) & \multicolumn{2}{|c|}{$45(12-77)$} \\
\hline BMI median (range) & \multicolumn{2}{|c|}{$27,5(16,3-44,5)$} \\
\hline \multicolumn{3}{|c|}{ ASA-score } \\
\hline I & 292 & 66 \\
\hline II & 149 & 34 \\
\hline Total & 441 & \\
\hline
\end{tabular}

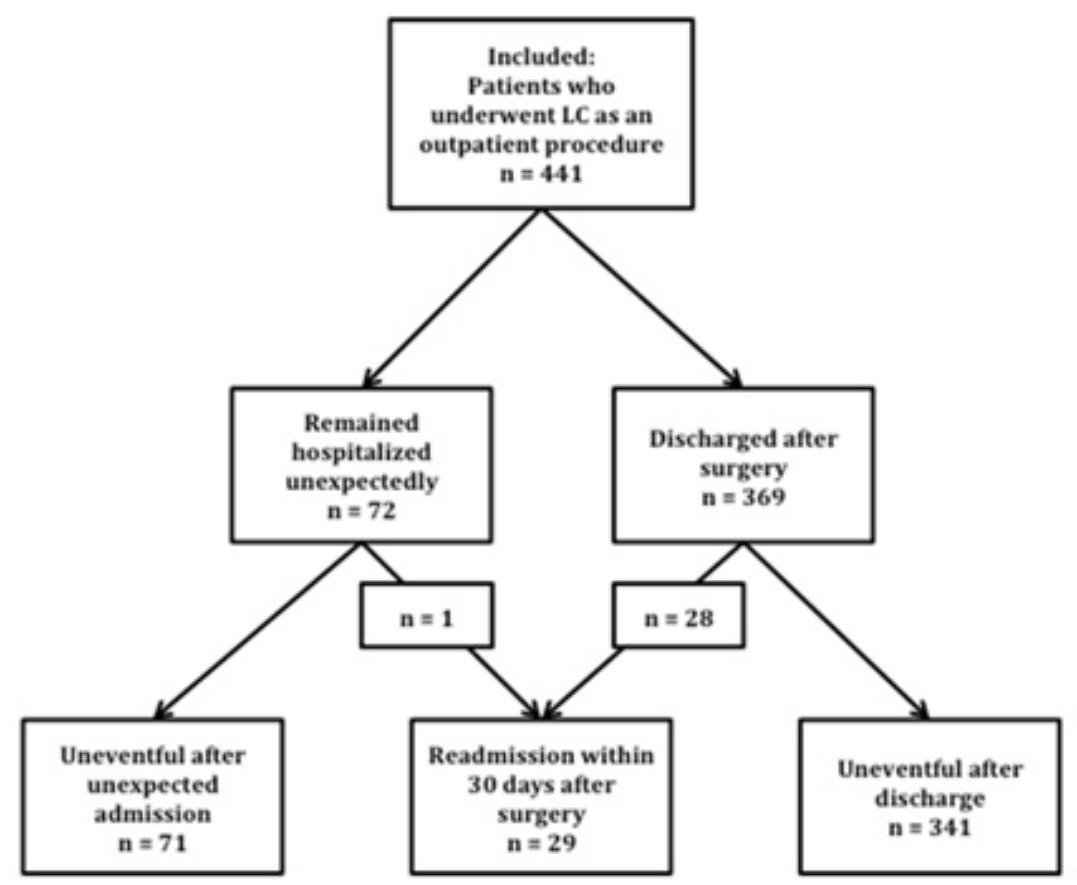

Figure 1. Flow chart 
Table 3. Indication for cholecystectomy

\begin{tabular}{|c|c|}
\hline Indications* $^{*}$ & $\boldsymbol{n}$ \\
\hline Symptomatic cholecystolithiasis & 434 \\
\hline Cholecystitis & 20 \\
\hline Choledocholithiasis & 17 \\
\hline Pancreatitis & 9 \\
\hline Gallbladder polyp & 4 \\
\hline
\end{tabular}

Table 4. Indication for cholecystectomy in those unexpectedly admitted

\begin{tabular}{|c|c|c|c|}
\hline Indication* & $\boldsymbol{n}$ (admitted) & Total & \% \\
\hline Only symptomatic cholecystolithiasis & 63 & 399 & 16 \\
\hline Cholecystitis & 6 & 20 & 30 \\
\hline Choledocholithiasis & 3 & 17 & 18 \\
\hline Pancreatitis & 1 & 9 & 11 \\
\hline Polyp & 1 & 4 & 25 \\
\hline Total & $\mathbf{7 4}$ & $\mathbf{4 4 9}$ & \\
\hline
\end{tabular}

*One patient may have more than one indication for unexpected admission

Table 5. Reasons for unexpected admission

\begin{tabular}{|c|c|c|}
\hline Reasons for unexpected admission $(\mathbf{n}=\mathbf{7 2})$ & $\boldsymbol{n}$ & \% (of unexpected admitted) \\
\hline Suction drain & 16 & 22 \\
\hline Excessive pain & 15 & 21 \\
\hline PONV & 24 & 33 \\
\hline Bleeding & 9 & 13 \\
\hline Other & 9 & 13 \\
\hline Time of day & 6 & 8 \\
\hline Conversion to OC & 5 & 7 \\
\hline Wish of the patient & 4 & 6 \\
\hline Urineretention & 3 & 4 \\
\hline Lack of person to 24-hour surveillance & 2 & 3 \\
\hline Total & $\mathbf{9 3}$ & \\
\hline
\end{tabular}

*One patient may have more than one reason for unexpected admission

\section{Readmission}

Within 30 days past surgery 29 patients (7\%) were readmitted. Table 8 lists the reasons for readmission of which pain; haematoma/ bleeding and choledocholithiasis were the more frequently reasons. Most patients were treated conservatively but the 5 patients with choledocholithiasis had the stones extracted via endoscopic retrograde cholangiopancreatography (ERCP). Three patients needed laparoscopic re-operation, one of these due to bleeding and in two cases due to aberrant bile ducts resulting in cholascos. A fourth patient had a port site infection at the umbilicus and had the wound opened.

ANOVA revealed no statistically significant findings in relation to age, BMI, or operating time between patients readmitted and those who were not.

\section{Discussion}

In the present study $16 \%$ of the patients scheduled for outpatient LC were not discharged after surgery as planned, which is comparable to the findings in other studies $[1,7,10]$. However, $21 \%$ of these mainly staying in hospital due to excessive pain or PONV that could be controlled within a few hours - were discharged later on the same day. These admissions could probably have been avoided if the patients had been operated earlier in the day or if the outpatient department had longer opening hours. One study found a significant risk of unexpected admission after LC when operation started later than 1:00 PM [11]. As an alternative to prolonged opening hours the future outpatient LC could be scheduled for the mornings only in order to reduce the number of unexpected admissions of short duration.
In the $79 \%$ of patients not being sent home as planned, the main reasons for staying in hospital included intraoperative placement of a suction drain, excessive pain and PONV.

The reasons for placing a suction drain have not been investigated in this study. However, in some cases, it is possible that the use of suction drain could have been avoided resulting in a higher chance of same day discharge as planned. Akoh et al. [12] find the placing of a suction drain to be the most frequently reason for unexpected admission after LC. They suggest different alternatives such as the use of a topical trombotic agent, Floseal, if there is oozing from the liver as well as thorough lavage in the presence of bile spillage in order to avoid the use of suction drains. Implementing these alternatives to a higher degree may decrease the unexpected admission rate for outpatient LC.

PONV has proved to correlate with duration of anaesthesia as well as the total amount of carbon dioxide insufflated [10], and a long operating time therefore increases the risk of PONV. In some studies $[8,10]$, PONV has been shown to be a frequent reason for unexpected admission after LC and it is emphasized that actions to reduce the risk of PONV must be done in order to increase the success rate of outpatient LC $[8,10]$. Using lower insufflation pressures during LC as well as complete deflation of the peritoneal cavity after LC may bring better control of PONV $[8,10]$. These actions may reduce the unanticipated admission rate following outpatient LC.

Operating time was in the present study found to be the only significant predictor for unexpected admission, which has been found also in at least one other study [9]. Details about circumstances that

Table 6. Comparison between unexpectedly admitted and discharged patients

\begin{tabular}{|c|c|c|c|}
\hline Variables & $\boldsymbol{n}$ & Mean & SD \\
\hline \multicolumn{2}{|c|}{ Age } \\
\hline Discharged & 369 & 45,8 & 14,4 \\
\hline Unexpected admitted & 72 & 42,6 & 14,1 \\
\hline Total & 441 & 45,3 & 14,4 \\
\hline \multicolumn{1}{|c|}{ BMI } \\
\hline Discharged & 369 & 27,68 & 4,71 \\
\hline Unexpected admitted & 72 & 27,76 & 5,15 \\
\hline Total Operating time (minutes) & \\
\hline & 369 & 69,8 & 25,78 \\
\hline Discharged & 72 & 97,4 & 39,7 \\
\hline Unexpected admitted & 441 & 74,3 & 29,7 \\
\hline Total & 441 & 27,69 & \\
\hline
\end{tabular}

Table 7. ANOVA (unexpected admitted/discharged patients)

\begin{tabular}{|c|c|c|c|c|c|}
\hline Variables & Sum of Squares & df & Mean Square & F & Sig. \\
\hline Age & 634,878 & 1 & 634,878 & 3,076 & 80 \\
\hline BMI & 0.481 & 1 & 0.481 & 0.021 & 0.885 \\
\hline Operating time & 46096,056 & 1 & 46096,056 & 59,290 & $\mathrm{P}<0,001$ \\
\hline
\end{tabular}

Table 8. Reasons for readmission

\begin{tabular}{|c|c|c|}
\hline Reasons for readmission $(\mathbf{n}=\mathbf{2 9})$ & $\boldsymbol{n}$ & \% \\
\hline Pain & 21 & 72 \\
\hline Haematoma/bleeding & 7 & 24 \\
\hline Choledocholithiasis & 5 & 17 \\
\hline Infection & 4 & 14 \\
\hline Nausea/vomiting & 3 & 10 \\
\hline Pancreatitis & 3 & 10 \\
\hline Cholascos & 2 & 7 \\
\hline Other & 2 & 7 \\
\hline Total & 47 & \\
\hline
\end{tabular}

*One patient may have more than one reason for readmission 
may have an impact on the operating time have only been sparsely investigated. Akoh et al. [12] looked into the experience of the surgeon in relation to operating time and outcome. They found a statistically significant longer operating time for inexperienced surgeons compared to senior surgeons, but no differences in outcome were found. In the present study this comparison could not be done as the less experienced surgeons often got assistance from a senior colleague during a shorter or longer part of the operation and this has not always been recorded in the patients' case files. However, there may be a greater number of unexpected admissions among patients operated by less experienced surgeons due to a longer operating time in these cases. Other factors influencing operating time are adhesions particularly due to former attacks of acute cholecystitis or earlier abdominal operations. Details about abdominal operations prior to LC were not investigated in this study. Adhesions due to former surgery may account for longer operating time and hence, a higher risk of unexpected admission after LC. It may be of value to investigate this matter more thoroughly for a better selection of patients fit for outpatient surgery in the future. Almost a third of patients having a former episode of acute cholecystitis experienced unexpected admission after surgery. Although not significantly associated in this study, maybe due to the small number, it is thought that previous episodes of acute cholecystitis gives a higher degree of complication to the surgery increasing the risk of prolonged operating time and therefore a higher risk of unexpected admission.

The conversion rate of $1 \%$ found in this study is similar to those found in other studies $[4,11,13]$. Median operating time was not affected by the operations being converted hence it did not influence the result that operating time was a significant predictor of unexpected admission. The conversion rate is acceptable as the daily scheduled operating programme was followed without postponements and not influencing the risk of unexpected admissions due to delays.

The current study finds a readmission rate of $7 \%$ mainly due to pain, haematoma/bleeding and choledocholithiasis. The majority were treated conservatively with few episodes of major complications needing intervention such as laparoscopic re-surgery or stone extraction with ERCP. The results are comparable to those found in other studies $[1,4,7,8,13]$. Boehme et al. [6] have looked into the relation between co-morbidity and postoperative resource utilization after LC and OC finding that certain comorbid conditions significantly increase utilization of postoperative resources including readmissions. In this study the patients had only ASA-score I and II hence no major comorbidity. Therefore conclusions regarding comorbidity and the risk of postoperative admission are beyond the scope of this study.

In this study a total of 9 patients (2\%) required subsequent resurgery after LC. Although literature concerning this matter is sparse, one study found 2 out of 164 patients (1\%) needing re-surgery [7] after LC suggesting that the rate found in this study is acceptable. However, 4 of the unexpectedly admitted patients were re-operated shortly after the original operation due to bleeding, and paying more attention to the haemostasis at the end of the surgery could be beneficial for the rate of re-surgeries needed after LC.

\section{Limitations}

This was a retrospective cross sectional cohort study, which may complicate interpretation of cause-effect relationships, and it does not always allow collecting all desirable data. It would have been appropriate to know details about the charge and experience of the individual surgeons, and which preventive measures had been taken to avoid bleeding, excessive pain and PONV. Furthermore some results showed a trend without reaching statistical significance, which might have turned out differently if the study had included more patients. Also it would have been relevant to look into the indications for the placement of suction drains, but that was beyond the scope of this study.

\section{Conclusion}

Operating time was found to be the only independent predictor of direct admission after outpatient LC. The use of intraoperative suction drains and PONV were frequent reasons for unanticipated admission. Actions to reduce these factors may be favourable in relation to lowering the rate of unexpected admissions after outpatient LC.

Prolonged opening hours at the outpatient clinic may reduce the number of patients being unexpectedly admitted after outpatient LC. Alternatively outpatient LC should be scheduled for the mornings only to improve the rate of same day discharge.

\section{Conflict of interest}

Neither of the authors has any financial or any other conflicts of interest to declare.

\section{References}

1. Al-Omani S, Almodhaiberi H, Ali B, Alballa A, Alsowaina K, et al. (2015) Feasibility and safety of day-surgery laparoscopic cholecystectomy: a single-institution 5-year experience of 1140 cases. Korean J HepatobiliaryPancreatSurg 19:109-112.

2. Hendolin HI, Pääkönen ME, Alhava EM, Tarvainen R, Kemppinen T, et al. (2000) Laparoscopic or open cholecystectomy: a prospective randomised trial to compare postoperative pain, pulmonary function, and stress response. Eur J Surg166:394-399. [Crossref]

3. Chok KS, Yuen WK, Lau H, Lee F, Fan ST (2004) Outpatient laparoscopic cholecystectomy in Hong Kong Chinese - an outcome analysis. Asian J Surg27:313316. [Crossref]

4. Chauhan A, Mehrotra M, Bhatia PK, Baj B, Gupta AK (2006) Day care laparoscopic cholecystectomy: a feasibility study in a public health service hospital in a developing country. World J Surg30:1690-1695. [Crossref]

5. Tenconi SM, Boni L, Colombo EM, Dionigi G, Rovera F, et al. (2008) Laparoscopic cholecystectomy as day-surgery procedure: Current indications and patients' selection. International J of Surg6:S86-S88. [Crossref]

6. Boehme J, McKinley S, Brunt LM, Hunter TD, Jones DB, et al. (2016) Patient comorbidities increase postoperative resource utilization after laparoscopic and open cholecystectomy. SurgEndosc 30: 2217-2230. [Crossref]

7. Rathore MA, Andrabi SI, Mansha M, Brown MG (2007) Day case laparoscopic cholecystectomy is safe and feasible: a case controlled study. Int J Surg5: 255-259. [Crossref]

8. Lau H, Brooks DC (2002) Contemporary Outcomes of Ambulatory Laparoscopic Cholecystectomy in a Major Teaching Hospital. World J Surg26:1117-1121. [Crossref]

9. Lau H, Brooks DC (2001) Predictive Factors for Unanticipated Admissions after Ambulatory Laparoscopic Cholecystectomy. Arch Surg136:1150-1153. [Crossref]

10. Ammori BJ, Davides D, Vezakis A, Martin IG, Larvin M, et al. (2003) Day-case laparoscopic cholecystectomy: a prospective evaluation of a 6-year experience. $J$ HepatobiliaryPancreatSurg 10:303-308.

11. Robinson TN, Biffl WL, Moore EE, Heimbach JK, Calkins CM, et al. (2002) Predicting failure of outpatient laparoscopic cholecystectomy. AmJSurg 184:515-519.[Crossref]

12. Akoh JA, Watson WA, Bourne TP (2011) Day case laparoscopic cholecystectomy: reducing the admission rate. Int J Surg9: 63-67.[Crossref]

13. Jain PK, Hayden JD, Sedman PC, Royston MS, O'Boyle CJ (2005)A prospective study og ambulatory laparoscopic cholecystectomy: Training economic, and patient benefits. SurgEndosc 19:1082-1085. [Crossref]

Copyright: (C2017 Madsen MR. This is an open-access article distributed under the terms of the Creative Commons Attribution License, which permits unrestricted use, distribution, and reproduction in any medium, provided the original author and source are credited. 